\title{
Organizational factors influencing scholarly performance: a multivariate study of biomedical research groups
}

\author{
Maaike Verbree • Edwin Horlings • Peter Groenewegen • \\ Inge Van der Weijden · Peter van den Besselaar
}

Received: 30 August 2013/Published online: 23 September 2014

(c) Akadémiai Kiadó, Budapest, Hungary 2014

\begin{abstract}
Bibliometric studies often measure and compare scholarly performance, but they rarely investigate why universities, departments, and research groups do have different performance. In this paper we try to explain differences in scholarly performance of research groups in terms of organizational variables. In order to do this, we extensively review the relevant literature, and develop a model using two theoretical approaches. A multivariate analysis shows which of the independent variables do play a role in the various scholarly performance dimensions. The study shows what organizational strategies may help in optimizing performance in various dimensions. Implications are discussed.
\end{abstract}

Keywords Research performance - Scholarly performance indicators - Resource dependence - Task group effectiveness - Research leadership · Research management . Networking

M. Verbree

University of Applied Sciences Amsterdam, Amsterdam, The Netherlands

E. Horlings

Rathenau Instituut, Den Haag, The Netherlands

P. Groenewegen

VU University Amsterdam, Amsterdam, The Netherlands

I. Van der Weijden

CWTS, Leiden University, Leiden, The Netherlands

P. van den Besselaar $(\bowtie)$

Department of Organization Sciences \& Network Institute, VU University Amsterdam, Amsterdam, The Netherlands

e-mail: p.a.a.vanden.besselaar@vu.nl 


\section{Introduction}

The growing complexity and interdisciplinarity of research problems asks for more and different expertise combined in research groups. Research is increasingly conducted in larger research groups, even in disciplines were researchers traditionally conduct research on their own. This change was already observed in the 1970s (Stankiewicz 1976). The development of 'group science' or 'team science' poses new responsibilities on academic group leaders to create adequate organizational conditions that help meeting the collective and individual research goals such as high research performance (e.g. Amabile et al. 2004; Bland and Ruffin 1992; Goodall 2009; Van der Weijden et al. 2008b; Falk-Krzesinski et al. 2011).

Pelz and Andrews (1966) were the first who thoroughly investigated the organizational determinants for a stimulating research environment, highlighting communication, motivation, and group size as important variables that influence research performance. Several later studies investigated the relationship between leadership practices and performance (e.g. Babu and Sing 1998; Bland and Ruffin 1992; Harvey et al. 2002; Knorr and Mittermeir 1980; Mumford et al. 2002; Stankiewicz 1976). However, these studies leave leadership as a black box, and do not show which specific leadership tasks and practices positively relate to performance.

Research output has a multidimensional nature (Jansen et al. 2007). Examples are publications, reports, presentations, technical contributions, contributions to public debates, education, patents, and innovations. Also quality is multidimensional and can be measured in terms of productivity, impact, innovativeness, creativity, societal relevance, and recognition. Furthermore, performance should be evaluated in terms of the groups' mission, and in relation to expectations about field-specific appropriate scholarly and societal performance (De Jong et al. 2011). As group leaders need to deploy different strategies to achieve different research goals (van der Weijden et al. 2008b), managing research groups becomes complex. Group leaders need to choose how to lead their research group, depending on the groups' mission and environmental contingencies. Following Zaleznik (1977), we distinguish between the management tasks and the leadership tasks of a group leader. Management refers to organizing the work and managing the process, i.e. securing that projects are successfully executed and finalized, and improving the way the group functions. Also acquiring funding, and hiring the required staff are management tasks. Leadership refers to stimulating and inspiring researchers, and to formulating a challenging research agenda.

Research is increasingly embedded in a heterogeneous institutional field, leading to new and more contingencies. (University) researchers are consequently embedded in an environment with heterogeneous demands (Gulbrandsen and Smeby 2005). Industrial and societal connections through funding and applied problem orientation are growing, resulting in the development of entrepreneurial research environments (Etzkowitz 1998). Changes in the funding landscape (Lepori et al. 2007) makes researchers more dependent on external funding, and reduces the influence institutional-level policies have on group leaders' research agenda and strategy. At the same time, research groups try to avoid dependency on a single external resource, in order to increase autonomy-also from the institutions' policies (Sanz-Menéndez and Cruz-Castro 2003). The manner in which increased diversity in the environment of research groups affects management, leadership and scholarly performance of groups remains an open question (Auranen and Nieminen 2010). 
In this paper, we explore the mechanisms behind the relationship between academic leadership and scholarly performance, taking a variety of contextual factors into account. Whereas many studies (which we review here) investigate bivariate relations between leadership/management variables and performance, we here develop a model to test how various academic leadership practices are interrelated and simultaneously influence scholarly ${ }^{1}$ performance.

In the next section, we discuss the literature on organizational variables influencing scholarly performance, and combine these variables into four components of academic leadership (Verbree et al. 2013a). The first component captures the inputs for research: resource strategy is the task of the group leader to acquire and combine resources. The second component of academic leadership refers to managing and organizing the research process. The third component refers to leadership in the narrow sense as defined above. Finally, a group leader needs to position the group in the scientific and societal environment. This is how the group obtains legitimacy, reputation, and visibility. We call this final component network management. We use Gladstein's (1984) input-process-output model of group effectiveness to understand how the four components of academic leadership interrelate and simultaneously determine performance. Group effectiveness is not only determined by the leader but also by the environment in which he or she operates, as is implied in network management and resource acquisition. Therefore, we augment our model with resource dependence theory (Pfeffer and Salancik 1978). The literature review leads to a model that specifies the relations between the variables to be tested. After presenting the model, the paper continues with a section on the data and the statistical methods; a section with the findings; and a section discussing the implications of our findings for the model. The latter section ends with the limitations of this study. We finish a paper with conclusions, implications, and questions for further research.

\section{Theoretical background}

\section{Resource strategy}

Funding and human capital are two key resources that group leaders must acquire to conduct research and realize research output (Johnes 1988). A lack of funding is obviously detrimental to research (e.g. Babu and Sing 1998; Heinze et al. 2009). To overcome the constraints of institutional funds, research groups increasingly try to acquire funding from a variety of external (and increasingly also international) sources (Geuna 2001). Yet, funding sources have different expectations from the work they fund and elicit different strategies from applicants: Competitive research council funding focuses on stimulating academic careers (Bornmann et al. 2010; Hornbostel et al. 2009; Van den Besselaar and Leydesdorff 2009), and industry funding aims at useful (applied) research results (Groot and García-Valderrama 2006; Gulbrandsen and Smeby 2005; Carayol 2003; Louis et al. 2007). However, quite some studies did not find a relation between funding levels and performance (Carayol and Matt 2006; Cherchye and Abeele 2005; Groot and GarcíaValderrama 2006).

\footnotetext{
${ }^{1}$ In this paper we restrict ourselves to the management and leadership factors that influence scholarly performance of research teams. We do not discuss other dimensions of performance, such as teaching performance, or societal outcomes. The general term 'performance' is used synonym for 'scholarly performance'.
} 
Available funding resources constrain human capital. How is size related to scholarly performance? Large groups can realize much output across a broad range of (interdisciplinary) research topics (Louis et al. 2007; Pineau and Levy-Leboyer 1983; Spangenberg et al. 1990). Then again, there may be diminishing marginal returns to labor (Dundar and Lewis 1998; Jordan et al. 1988, 1989; Omta 1995). Although smaller groups produce less output about a more restricted range of research topics, they are easier to manageespecially for less-experienced group leaders-and the coordination costs to organize scholarly communication and collaboration among group members are much lower (Urwick 1956; Carayol and Matt 2004, 2006; Heinze et al. 2009). Given the advantages of both big and small, it is suggested that research groups need critical mass but above a threshold productivity declines (Blackburn et al. 1978; Stankiewicz 1979; Von Tunzelmann et al. 2003). This threshold varies between research fields (Baird 1986; Kyvik 1995; Cherchye and Abeele 2005), and depends on the internal structure of the group. Distributed leadership, experienced group leaders, and a high level of group cohesiveness enable larger group sizes (Omta 1995; Mehra et al. 2006; Stankiewicz, Stankiewicz 1979).

What would be an optimal size also depends on a groups' environment. In larger and heterogeneous groups it is easier to organize a variety of activities next to research, such as teaching or patient care. These groups may therefore have an advantage over smaller groups as their size and diversity reduce their dependence on critical resources (Pfeffer and Salancik 1978). However, smaller research groups may have different missions; e.g., we found that smaller groups generate more societal output (Van der Weijden et al. 2012). The degree of environmental dependency influences group performance, which is also influenced by the way in which group leaders integrate group activities in the organizational context through management, leadership and networking (Gladstein 1984:513).

The effects of group composition have hardly been investigated, although it is theoretically and practically an important issue (Falk-Krzesinski et al. 2011; Stvilia et al. 2011). Do groups benefit from a flat structure with many young $\mathrm{PhD}$ students, or would an intermediate layer of senior staff improve performance? And, do (larger) teams with more than one group leader perform well? We include in the model several resource variables, such as group size, group composition, and the variety funding sources.

\section{Group management}

Group leaders have several tools to manage the research process. First, they can enhance performance by offering rewards (Omta and de Leeuw 1997; Spangenberg et al. 1990). The literature suggests that intangible rewards are generally more effective than material rewards. Material rewards are only useful under limited conditions, for example, when researchers feel that their salaries are not growing sufficiently fast or when they believe their salaries to be lower than those of their peers (Gustad 1960; McKeachie 1979). Praise and prizes, or a pat-on-the-back, positively correlate with the amount of publications, acquired funding, and the number of research proposals submitted and granted (Van der Weijden et al. 2008b).

Secondly, group leaders can stimulate communication between researchers in order to improve the functioning of the team. Examples are internal research meetings, retreats, and project meetings (e.g. Frederiksen et al. 2004; Mets and Galford 2009). Communication provides an intellectual stimulus (Pelz and Andrews 1966) and more communication results in better performance (Allen and Sloan 1970; Harris and Kaine, 1994; Kretschmer 1985; Ramsden 1994; Visart 1979). Research groups typically perform project-based work of a non-routine and complex nature. Such work requires effective coordination and 
integration of ideas, and therefore an integrative communication structure (Cummings and Cross 2003; Katz and Tushman 1979; Tushman and Katz 1980). It is easier to create interactions within established research groups than in new ones (Martin-Sempere et al. 2008). Moreover, communication with other parts of the organization may foster group performance, as it may help to acquire support from other units and from top management of the institute (Gladstein 1984).

A third tool of the group leader is quality control, which is related to the balance between autonomy and coordination. Autonomy stimulates creativity while coordination is needed to organize interactions and achieve a collective goal (Pelz 1956; Pelz and Andrews 1966; Hackett 2005; Pineau and Levy-Leboyer 1983; Andrews and Farris 1967). Some even suggest that researchers need to be free to define and pursue their individual interests in order to be maximally creative (Heinze et al. 2009; Haraszthy and Szántó 1979). However, autonomy and coordination are related. The overall degree of individual autonomy is bounded by a collective research agenda (Leisyte et al. 2008). Among less experienced researchers-juniors as well as newcomers-supervision is more important than autonomy for stimulating performance (Van der Weijden et al. 2008a; Katz 1978a, b). As researchers gain experience, there is less need for supervision. In the model, we include the following variables: the use of rewards, the intensity of communication, autonomy of researchers, and the quality control attitude.

\section{Leadership}

Leadership can be described as steering researchers through inspiration and vision. The leader should have and maintain a high level of scholarly expertise (Mumford et al. 2002). The group leader should have skills in the care and feeding of all group members, as this is critical to the groups' success and productivity (Sindermann 1985). Goodall (2009) found that in research universities, high performance not only depends the research leader being a top scholar, but also on good leadership and management skills. Leadership also results in creative research. Leaders provide facilities for addressing new problems or ideas, provide a protected space for conducting research, and provide complementary skills by selecting new group members (Heinze et al. 2009).

Motivation is important for performance, and it varies between research groups (Andrews 1979). Research groups with highly motivated group members have higher performance: their members judge their groups to be more productive and innovative. The group leader plays a key role in motivation. He/she should show strong commitment and involvement with the groups' research, e.g., by showing interest, by contributing technical competence, and by participating in research (Andrews and Farris 1967), as a strong research orientation is beneficial for performance (Blackburn et al. 1978; Fox 1992; Gottlieb and Keith 1997; Harris and Kaine 1994; Porter and Umbach 2001; Prpic 1996; Ramsden 1994; Shin and Cummings 2010). In the model, we include the following variables: time used for research, focus on maintaining scientific expertise, and commitment and involvement with the group's research.

\section{Network management}

Group leaders need to manage both their internal and external relationships. Internal relationships are relevant for coordination, knowledge sharing, and collective action. External relations need to be build too, as research groups depend on it for gaining access 
to resources such as knowledge, information, reputation, experience, and funding (Reagans and Zuckerman 2001; Reagans et al. 2004; Oh et al. 2004, 2006).

Building internal and external relationships are complementary processes in which group leaders play a crucial role. Having strong internal ties as well as many weak external ties increases team productivity. Leaders' centrality in external and internal networks is related to group performance, and to their leadership reputation as perceived by their subordinates, peers, and supervisors (Mehra et al. 2006). In other words, leaders play a crucial role in building the group's social capital. ${ }^{2}$ It is particularly important for smaller groups to invest in their integration into national and international networks, as "it is generally not 'smallness' which is the main problem but 'loneliness'." (Von Tunzelmann et al. 2003). Networks can extent to research groups located in the same research institute, in other domestic research institutes, or research institutes abroad. ${ }^{3}$

The various relationships affect performance (e.g. Adams et al. 2005; Fox and Mohapatra 2007; He et al. 2009; Omta and De Leeuw 1997). Interactions with peers, for example communication at conferences and international collaborations, provide the intellectual exchange that is essential for knowledge creation and the development of new ideas (Melin 2000; Wagner 2005). International relations have a stronger positive effect on performance than local relations. This holds for communication with research groups abroad (e.g. Spangenberg et al. 1990), as well as for international collaboration (Shin and Cummings 2010; Smeby and Try 2005). What is the causal relationship between collaboration and performance? Collaboration can be required to obtain ideas, skills, expertise, and equipment that add to performance (e.g. Bozeman and Corley 2004). On the other hand, the best performing researchers might attract other researchers who are willing to collaborate (Fox and Mohapatra 2007). A recent study suggests that international collaboration predicts future research output rather than the other way around (He et al. 2009). In general, external connections can be regarded as boundary-spanning, increasing the diversity of external resources and inputs, which is understood to enhance performance (Cardinal 2001).

Interactions also take place with stakeholders in industry, government, and other segments of society (e.g. De Jong et al. 2011; Laredo and Mustar 2000). Scholarly networks can stimulate academic careers, but science-industry relations do not (van Rijnsoever et al. 2008). Others, however, qualify this conclusion (Manjarrés-Henríquez et al. 2008), or argue the opposite (Lam 2011; D'Este and Perkmann 2011; Haeussler and Colyvas 2011). In the model, we include the variable the amount of time spend on the various external activities and on networking.

\section{Personal characteristics}

Several personal characteristics of the group leader influence performance. Output changes when researchers become older. The relation between age and output most likely has the shape of inverted U-curve with a peak in performance when the researcher is between his early forties and mid-fifties (Gonzalez-Brambila and Veloso 2007; Levin and Stephan 1991; Pelz and Andrews 1966). This is not to say that the observed drop in individual

\footnotetext{
2 "The set of resources made available to a group through members' social relationships within the social structure of the group and in the broader formal and informal structure of the organization." (Oh et al. 2004, 2006).

${ }^{3}$ See Katz and Martin (1997), for a conceptualization of research collaboration and their different forms. For a recent review: Bozeman \& Boardman (2014).
} 
performance above a certain age hinders group performance. Responsibilities change when researchers become older and more experienced, and the intensity of non-research activities increases (Knorr and Mittermeir 1980). However, this may lead to more resources for the group, such as $\mathrm{PhD}$ students and competent researchers (Carayol and Matt 2004; Dundar and Lewis 1998), which may have a positive effect on their groups' performance.

A long professional experience allows a group leader to shape the knowledge and values of group members, to make good use of professional contacts and networks, and to help colleagues (Dill 1982). Becoming older and gaining experience changes the leadership and management style (Oshagbemi 2004; Verbree et al. 2013b; Van Rijnsoever et al. 2008). But overall, it takes time to build up a research group (Verbree et al. 2013a; Braam and Van den Besselaar 2010, 2014). Age is included in the model and years experience as team leader.

\section{Environmental conditions}

The environment in which a research group is embedded may heavily influence performance (e.g. Cherchye and Abeele 2005). Several studies show that moving to a more prestigious institution positively impacts individual research performance (Allison and Long 1990; Crane 1965; Keith and Babchuk 1998; Long 1978; Long et al. 1979; Long and McGinnis 1981; Ramsden 1994; Reskin 1979). Additionally, within 3-6 years researchers conform to the context of the university, industry, or government sector to which they have moved, independent of initial productivity (Long and McGinnis 1981). Dietz and Bozeman (2005) found evidence that researchers with an purely academic career have higher productivity than those who also had positions in industry or government.

Performance differences among research groups are also related to differences in mission of the organization they belong to. The organizational environment influences what research groups can select as mission and related activity profile. Laredo and Mustar (2000) identified five different types of activities in which groups can be involved: the production of (scientific) certified knowledge; the involvement in education, training activities, and embodied knowledge; contributing to competitive advantage (innovation process, e.g. proprietary knowledge); producing new public goods or services; and participating in public debate. The selection of the organizations' main activities has strong implications for research performance (Prins 1990). Not unexpectedly, departments with strong emphasis on research publish more than departments focusing on health care or on training practitioners (Baird 1986; Perkoff 1985).

Performance standards are not only set by research institutes but also by the scientific community. Scientific disciplines have highly different publication and citation patterns, which means that differences in the number of publications and citations between fields should not be misread as performance differences (e.g. Baird 1986; Crane 1972; Martin and Irvine 1983; Neuhaus and Daniel 2009; Schubert and Braun 1996; Van Raan 2004; Whitley 2000). As a result, performance can only be evaluated in an appropriate context (Bornmann et al. 2008; De Jong et al. 2011).

Finally, research groups are embedded in a national science system. The organization of agenda setting, funding, evaluation, and research differ between national science systems, as do career policies, governance and regulations (Bonaccorsi and Daraio 2005), influencing performance levels. In the model, we take into account system changes, disciplinary differences, and the type or organization (university medical center or public research organization). 
Figure 1 presents our model. The four components in the middle consist of the abovediscussed resource and process variables. The performance component includes the output variables discussed in the next section. We have excluded the possible effects of personal characteristics on the choice of management and leadership strategies. This is an interesting topic for research but outside the scope of this study. The environmental conditions (the context variables) may have direct effects on performance, but also on resource and process variables. However, the relation between environment and performance may be (partly) mediated by resource and process variables, or the other way around, by introducing environmental variables the relation between resource or process variables may disappear (confounder). Finally, the relation between resource and process variables and performance may prove to be different for the different context conditions (moderation).

\section{Data and methods}

A questionnaire was developed to collect information on a wide range of characteristics and activities of academic leadership as discussed above, focusing on resource strategy, leadership and management, and networking. Survey questions also covered the characteristics of the leader and environmental conditions. The data were collected in two surveys $(2002,2007)$ among biomedical and health research group leaders employed at University Medical Centers (UMCs) or public (bio)medical research organizations (PRO) in the Netherlands. Names and addresses of group leaders (mainly full professors) were obtained from administrative records. In 2002, 137 Dutch academic group leaders returned completed questionnaires by mail for an overall response rate of $38 \%$. In 2007, 188 group leaders returned a completed questionnaire for an overall response rate of $27 \%$. We used the tailored design method to maximize the response rate (Dillman 2009). We have combined both data sets to increase our sample size to a total of 325 respondents.

Contextual variables were measured in the following way. First of all, in the 5 years between the two surveys, several changes in the science system did take place, such as the implementation of specific funding programs to support 'excellence', research careers, and large-scale research. Assessment criteria for funding were extended with new emphasis on societal relevance. Finally, recent science policies encourage setting up inter-institutional collaborations. In order to check whether these changes influence the relationship between academic leadership and performance, we use the variable 'year of questionnaire' (2002 vs. 2007) in the model as a proxy for relevant changes in the science system.

Secondly, group leaders were asked to classify the research of their groups using a list of 28 (sub) disciplines in health research, e.g., health policy research, immunology, oncology. When research leaders indicated different disciplines, we used the one they mentioned as the most important discipline. Using this information, we distinguish three types of research, for which we use in this study the term 'discipline'.

- Pre-clinical research is basic (life science) research and is usually laboratory-based (consisting of disciplines like immunology, micro-biology, and neurosciences).

\footnotetext{
${ }^{4}$ Non-response analysis shows that the respondents can be regarded as a representative sample of the Dutch biomedical and health research groups. The respondents were evenly distributed among the various research institutions and the sub-disciplines. Performance levels between respondents and non-respondents did not significantly differ.
} 


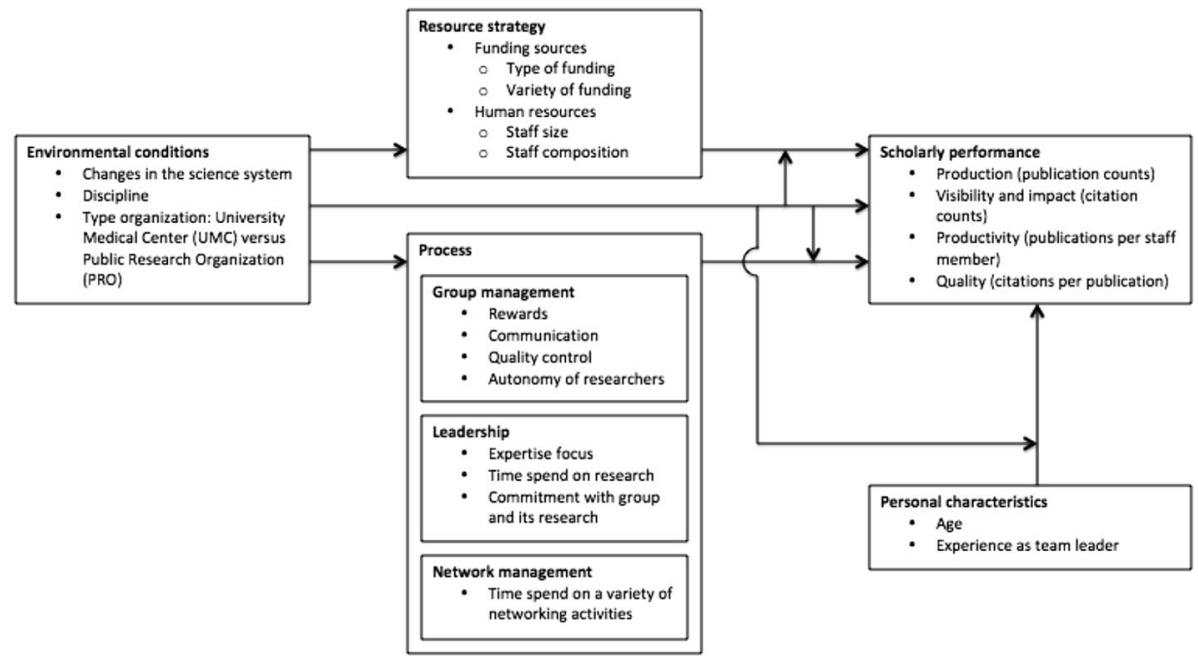

Fig. 1 Model of the relationship between academic leadership and scholarly performance of research groups

- Clinical research is application-oriented and involves direct patient contact (disciplines like dermatology, nephrology, and psychiatry).

- Public health research, often with a social sciences perspective (disciplines like social medicine, public health policy, organization of health care, and medical psychology).

The independent variables related to resources, management and leadership are all based on the surveys. Items were included to measure factual information such as group size, group composition, the sources of funding, and time use by the group leaders for different tasks such as research, patient care and teaching. We also asked for the age, gender and the years of experience as group leader.

Other variables are in most cases based on several items. Use of intangible rewards is measured as the average of three reward types. ${ }^{5}$ Communication intensity in the research group is based on four types of meetings. ${ }^{6}$ Commitment with the research of the group is measured using seven items. ${ }^{7}$ Focus on maintaining high scientific expertise is measured with two items. ${ }^{8}$ Two variables were measured with only one item: quality attitude, and group members' autonomy.

We use four different aspects of scholarly performance as dependent variables (Table 1). Total publication count of the group leader represents the amount of knowledge production of the group. The total citation count of the group leader's publications reflects the visibility of the group. The number of publications per group member measures productivity. The number of citations per publication is a proxy for quality. When a group

\footnotetext{
${ }^{5}$ Conference visit, stay abroad, courses. Cronbach's Alpha $=0.65$.

6 Meetings to discuss projects ideas; research proposals; new literature; draft papers) Cronbach's Alpha = 0.7 .

7 Relating to different roles in the team: intensively participating in research, source of knowledge, generating new ideas, more researcher than manager, etc. Cronbach's Alpha $=0.8$.

${ }^{8} \mathrm{Up}$ to date with the developments in the field; up to date with literature. Cronbach's Alpha $=0.76$.
} 
Table 1 Dimensions of performance

\begin{tabular}{llclll}
\hline & Mean & Variance & Std. dev. & Median & $N$ \\
\hline Publication counts & 27 & 529 & 23 & 22 & 322 \\
Citation counts & 363 & 83,944 & 289 & 172 & 320 \\
Publications per staff member & 2.5 & 5 & 2.23 & 195 & 312 \\
Citations per publication & 8.2 & 59 & 7.7 & 6.2 & 320 \\
\hline
\end{tabular}

attracts many citations for each publication, they successfully work at the research front and publish innovative ideas that peers consider interesting (Wouters 1999).

Data about the academic performance of the 325 research groups were collected from three databases: PubMed, the Web of Knowledge, and the Dutch Research Database. Publication counts were retrieved from PubMed (the US National Library of Medicine's search service) and Web of Knowledge, covering a three-year period before the survey (1999-2001; 2004-2006). We retrieved publications using the group leaders' surname and first two initials, and the institutional affiliation. Citation counts and the number of citations per publication were obtained from the Web of Knowledge for the publications published in the specific three-year period with a citation span of respectively 1999-May 2003 and 2004-May 2008. Productivity was calculated by dividing the number of publications by group size. The two databases sometimes gave different publication counts for the same research group, caused by errors in either database and by a difference in coverage. We used the lower publication count of the two databases to minimize errors. The 'Dutch Research Database' was used to check whether research group leaders were affiliated to more than one organization. When they were, we included their publications from both affiliations.

The four performance indicators can all be described as count data (Cameron and Trivedi 1998). They refer to the number of times publications and citations occur, the number of papers per group member (productivity) and the number of times each individual publication is cited (citations per publication). ${ }^{9}$ Our data are characterized by overdispersion: the sample variances exceed the sample means (Table 1). We therefore used negative binomial regressions to test our models (Allison 1980; Cameron and Trivedi 1998; Gardner et al. 1995), using SPSS generalized linear models (GLM).

The model is tested in the following way. After inspecting the correlations (Table 3), a negative binomial regression analysis is done for each of the resource, process, and individual components separately. Those variables in that have a significant relation with the performance indicators are included in the basic binomial regression model (Table 4). We also calculate the regression coefficients separately for the three context variables (Table 4-below the basic model). Next, we test the full model, including also the significant context variables. The value of the regression parameter $\exp (\beta)$ gives the percentage change in the performance variable for a unit change in the independent variable. For the nominal (environmental) variables, $\exp (\beta)$ represents how much higher or lower a performance is for a condition compared to the reference group. Change of regression coefficients between the basic model and the full model indicates mediation or confounding effects. Regression analysis separately for the various conditions of the environmental variables is done to find whether relations in the model are moderated by the environmental variables.

$\overline{9}$ For productivity and quality, the scores were multiplied by 100 to get count data (integers). 
Table 2 Correlations between performance indicators

\begin{tabular}{llll}
\hline & Citation counts & Productivity & Citations per publication \\
\hline Publication counts & $0.795^{*}$ & $0.769^{*}$ & $0.239^{*}$ \\
Citation counts & & $0.643^{*}$ & $0.719^{*}$ \\
Publications per staff member (productivity) & & & $0.231^{*}$ \\
\hline
\end{tabular}

$N$ between 310 and 320

$* p<0.000$

\section{Initial findings}

Correlation between publication counts and citation counts is very strong, suggesting that visibility and output go together. Productivity correlates strong but not very strong with production and visibility. Finally, the correlation between quality (citation per publication) and the other three indicators is low to moderate (Table 2). This indicates that each indicator has a different meaning (e.g. King 1987; Martin 1996; Schubert and Braun 1996; Tijssen 2003), and a research group may score very high on some indicators, but low on the others. Differences in (publication) strategies result in different performance profiles (Moed 2000). In other words, research groups can aim for different goals, use different strategies to reach them, and perform accordingly in terms of the four indicators.

Table 3 shows the correlations between the independent variables and the performance variables. In terms of group composition, staff size is positively related to publications and citations, but negatively with productivity. In contrast to the share of $\mathrm{PhD}$ students, the shares of full professors, of senior staff, and of other staff correlate negatively with most of the performance dimensions. Variety of funding is generally has a positive effect on performance, and this goes together with less institutional funding and more council, charities and EC. In terms of management and leadership, communication intensity, intangible rewards committed leadership, quality control, time devoted to research and network activities all correlate positively with all or some of the performance variables. Individual characteristics are relevant too: age works negatively, and experience works positively.

Overall, staff size, the share of $\mathrm{PhD}$ students, the number of funding sources, communication intensity in the group, commitment and participation of the group leader in the teams' research, and networking activities have the strongest impact on performance. These variables are not all independent. E.g., variety of funding sources correlates strong with group size. In the next section we test the multivariate models, and the results are summarized in Table 4.

\section{Testing the model}

\section{Publication counts (Output)}

The larger the scientific staff, the more publications. The effect of group size is, however, modest. Another aspect of resource strategy is group composition. Higher percentage of $\mathrm{PhD}$ students leads to significantly more publications. Two process variables make it into the full model. There is a small but significant positive relation between the intensity of 
Table 3 Performance by independent variables (Spearman's rho)

\begin{tabular}{|c|c|c|c|c|}
\hline & Publications & Citations & Publ/staff & Citations/publ \\
\hline Age & & $-0.134 * *$ & & $-0.123 * *$ \\
\hline Experience as leader & $0.167^{*}$ & $0.167^{*}$ & & $0.132 * *$ \\
\hline Staff size & $0.341^{*}$ & $0.230^{*}$ & $-0.268 *$ & \\
\hline$\%$ Full professors & $-0.142 * *$ & $-0.195^{*}$ & $0.126^{* *}$ & $-0.175^{*}$ \\
\hline$\%$ Senior staff & $-0.201 *$ & & $-0.111 * * *$ & $0.112 * *$ \\
\hline$\% \mathrm{PhD}$ students & $0.300^{*}$ & $0.244^{*}$ & $0.196^{*}$ & $0.124 * *$ \\
\hline$\%$ Other staff & & $-0.146^{*}$ & $-0.198 *$ & $-0.165^{*}$ \\
\hline$\%$ Institutional funding & & $-0.181 *$ & & $-0.172 *$ \\
\hline$\%$ Council funding & & $0.122 * *$ & $-0.111 * * *$ & \\
\hline$\%$ Contract funding & $0.106^{* * * *}$ & & & \\
\hline$\%$ Funding charities & & $0.194^{*}$ & & $0.268 *$ \\
\hline$\%$ Funding EC & & $0.109 * * *$ & $-0.109 * * *$ & $0.150 *$ \\
\hline Number of funding sources & $0.195^{*}$ & $0.258^{*}$ & & $0.138 * *$ \\
\hline Intangeble rewards & $0.134 * *$ & $0.182 *$ & & $0.128 * *$ \\
\hline Communication intensity & $0.191^{*}$ & $0.278^{*}$ & $0.123 * *$ & $0.225^{*}$ \\
\hline Quality control & & $0.118 * *$ & & $0.166^{*}$ \\
\hline \multicolumn{5}{|l|}{ Expertise up to date } \\
\hline Committed research leader & $0.195^{*}$ & $0.259 *$ & $0.169 *$ & $0.212 *$ \\
\hline$\%$ Time for research & & $0.155^{*}$ & & $0.225^{*}$ \\
\hline Days for networking & $0.263 *$ & $0.290 *$ & $0.127 * *$ & $0.129 * *$ \\
\hline Discipline (publ health as $\%$ of basic)\# & $42.8^{*}$ & $24.8^{*}$ & $42.7 * *$ & $36.5^{* *}$ \\
\hline Discipline (clinical as $\%$ of basic)\# & & & & $93.2 *$ \\
\hline Type organization (Univ as \% of PRO)\# & $180^{*}$ & & & $47 *$ \\
\hline System change (2007 as \% of 2002)\# & & & & $81.6^{* * *}$ \\
\hline
\end{tabular}

$N$ between 297 and 320

$* p<0.01$; ** $p<0.05$; *** $p<0.10$

\# Ratio of the means

network activities and the total number of publications. And group leaders with a stronger commitment with the group and its research produce more publications. Disciplinary differences are obvious: average publication count of public health research groups is only $48 \%$ of that of other groups. The type of organization makes a difference too: UMC-based research groups have a $68 \%$ higher output than PRO-based groups.

The values of $\exp (\beta)$ in the basic model and the full model are about equal—so we find mainly direct effects and no mediation. Analyzing separately for the different conditions of the context variables (not in the table) shows that the organization type has a moderating effect. $\operatorname{Exp}(\beta)$ for percentage $\mathrm{PhD}$ students and for committed leadership is much higher for PRO-groups than in UMC-groups.

\section{Citation counts (Visibility)}

More staff means more citations. The effect size is about similar to that for total publications. Citation counts correlate also with the share of $\mathrm{PhD}$ students and the share of senior researchers, suggesting two different staff composition types beneficial for visibility. 
Variety of funding sources shows a significant positive relation with total citations. However, causality could also work in the other direction: more visible groups are more successful in attracting funding from a larger variety of funders. From the process variables, intensity of internal communication, commitment with research and the group, and network activities appear to raise visibility. Related to the context, citation counts differ between disciplines: public health research has substantially less citations than clinical research and the fundamental life sciences. There is no significant effect of organization type on citation counts.

The regression coefficients of the two models are rather similar, suggesting the absence of mediation effects. On the other hand, the regression coefficients for $\% P h D$ students and $\%$ Senior Staff differ strongly between the disciplines and between organization types.

\section{Productivity (publications per researcher)}

There is clear evidence of diminishing marginal returns to labor. The effect is modest but significant. A higher percentage of $\mathrm{PhD}$ students and full professors has a positive impact on group productivity, and compensates for the diminishing returns of size increase. Among the process variables, commitment to research and the research group and network activities make a significant difference. Context matters too. UMC-based groups have a higher productivity than PROs, and public health research scores lower on productivity than the other two disciplines.

The regression coefficient of the \%FullProfs is much lower in the full model than in the basic model, showing that the effect found in the basic model is largely spurious and caused by differences between organization types. Finally, the regression coefficient for $\%$ FullProfs is negative for public health groups, and positive for clinical and basic research groups - so here we find a moderation effect.

\section{Quality (citations per publication)}

In the basic model, we found several managerial or leadership variables significantly influencing the number of citations per publication: the share of senior staff and of $\mathrm{PhD}$ students, communication intensity and quality control. However, in the full model, the regression coefficients are much lower and not significant any more, This suggests that the relations found in the basic model are in fact largely spurious. Indeed, public health research groups receive $35 \%$ fewer citations per publication than basic life sciences groups. And clinical research groups receive in average $38 \%$ more citations per publication) than basic life sciences groups. Finally, university based groups receive $37 \%$ less citations per publications that PRO groups.

\section{Analysis}

What do these findings imply for the model we introduced? And what more general conclusions can be drawn from it about the role of resources, process and personal characteristics, and about the influence of environmental factors? 
Environmental conditions

Context matters. Some determinants of performance are beyond the control of research leaders, such as disciplinary differences, the type of organization, and changes in the science system. Especially the public health research groups differ significantly from clinical and basic research groups. They have lower scores on each performance indicator-indicating the discipline specific publication and citation cultures (Table 5). Public health research leaders have also differently structured groups (higher share of seniors and lower share of $\mathrm{PhD}$ students), show a different funding pattern (especially the role of councils, EC, and charities) and organizational practices (intensity of communication; time devoted to teaching). Nevertheless, the effects found for resource strategy and process variables in the basic model do not disappear when controlling for the discipline differences (Table 4).

Also organization type is relevant (Table 5), as UMC-based groups have much higher publication counts than PROs but much lower citations per publications. Resource strategy seems to differ strongly too, as PRO-teams are in average smaller and have a higher share of senior researchers. PRO-teams tend to rely on different funders than UMC-based groups. Differences in managerial and leadership practices are smaller, but PRO-team leaders spend much more time on research and have in average a somewhat stronger commitment with the team and its research than their university based colleagues. But also here, introducing organization type in the full model does not have much effect on the regression coefficients for the resource and process variables (Table 4).

Finally, we analyzed whether changes in the science system were reflected in changes in characteristics of resources and research groups. Table 5 gives the ratio between variable means for 2007 and 2002 (Table 5). Groups became larger, and the share of PhD students increased, whereas the share of senior staff decreased. More groups have two leaders in 2007 than in 2002. Funding changed too over time: institutional funding declined, but council funding, contract funding and EC funding increased-as did the average variety of funding sources used by groups. The use of intangible rewards declined somewhat. Average communication intensity remained constant, but the autonomy of team members and the pre-evaluation of grant applications increased. Focus on scientific expertise went down. All other process variables remained unchanged. At the individual level, average age of the leaders remained about 53 years, and average experience as a leader 12 years. As the test of the model showed (Table 4), system changes did not influence the effects of other variables on performance-as the system change variable did not make it into the four full models.

\section{Resource strategy}

Increasing group size leads to increase of numbers of publications and citations, but to lower productivity, suggesting diminishing marginal returns to labor in biomedical research. No association exists between group size and citations per publication.

Group composition has considerable impact. A higher percentage of PhD students leads to higher output, to more citations, and to higher productivity. Table 3 shows that percentage of senior staff, and other researcher staff correlates (not or) negatively with performance. This suggests that less hierarchical groups-groups without layers of staff between group leaders and PhD students - have the tendency to perform better than more hierarchical groups. Only for visibility this seems less the clearly the case, as here also a 


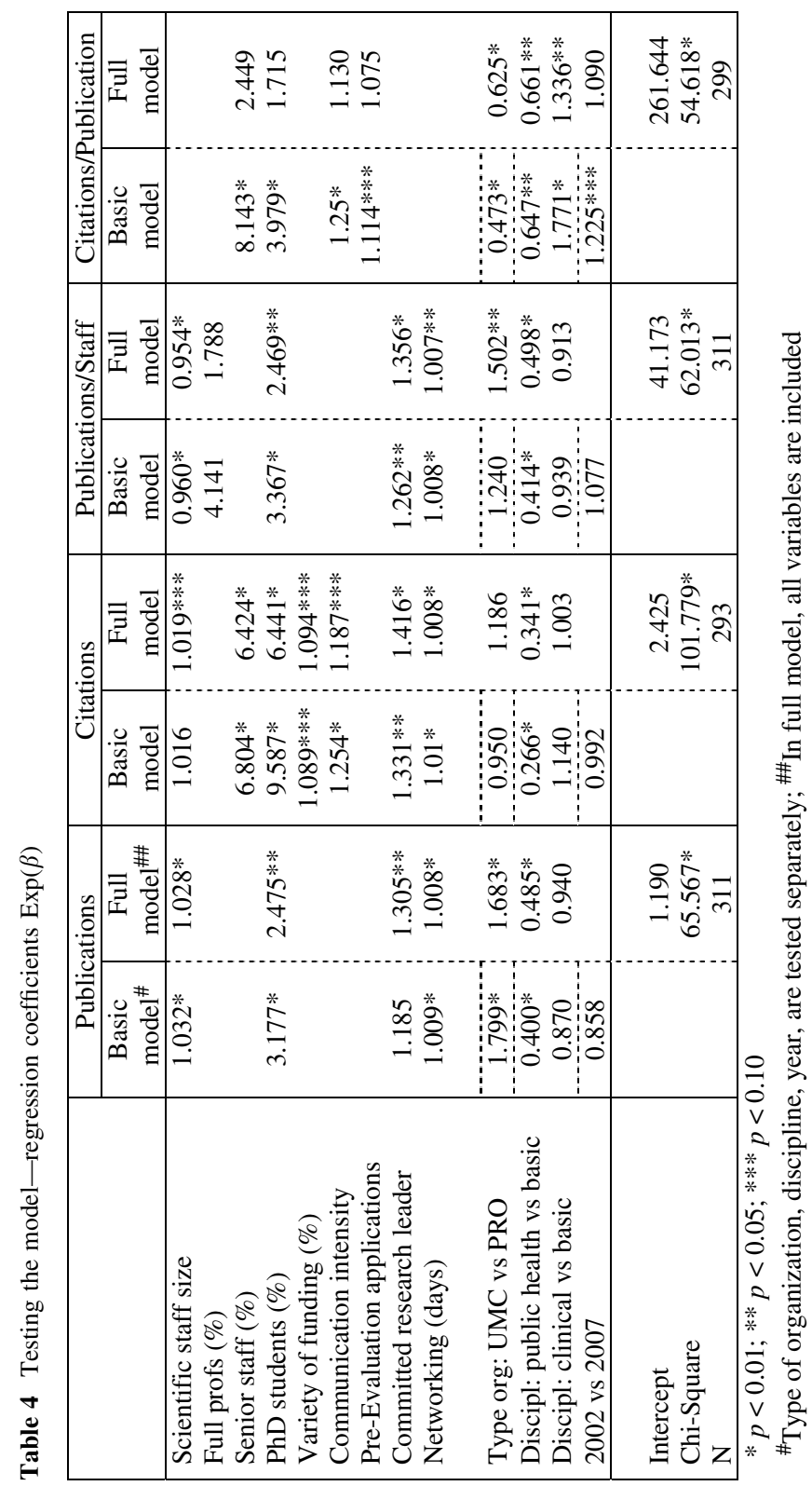


Table 5 Ratio of mean scores of environmental variables ${ }^{\#}$

\begin{tabular}{|c|c|c|c|c|c|}
\hline & \multirow{2}{*}{$\begin{array}{l}\text { System } \\
\text { change } \\
2007 / 2002\end{array}$} & \multicolumn{3}{|c|}{ Disciplinary differences } & \multirow{2}{*}{$\begin{array}{l}\text { Type } \\
\text { organization } \\
\text { UMC/PRO }\end{array}$} \\
\hline & & $\begin{array}{l}\text { Pub health/ } \\
\text { clinical }\end{array}$ & $\begin{array}{l}\text { Pub health/ } \\
\text { basic }\end{array}$ & $\begin{array}{l}\text { Clinical/ } \\
\text { basic }\end{array}$ & \\
\hline Scientfic staff size & $1.2 *$ & 1.0 & 1.1 & 1.1 & $1.5^{*}$ \\
\hline Full profs $(\%)$ & 1.0 & 1.1 & $1.4^{*}$ & $1.2 *$ & $1.8 *$ \\
\hline Senior staff (\%) & $0.9 * *$ & $1.1^{*}$ & $0.9^{*}$ & $0.8^{*}$ & $0.7 *$ \\
\hline PhD students $(\%)$ & $1.1 * *$ & $0.8^{*}$ & $0.8^{*}$ & 1.0 & 1.0 \\
\hline Institutional funding (\%) & $0.77 *$ & 0.9 & 1.0 & 1.1 & $1.6^{*}$ \\
\hline Council funding $(\%)$ & $1.2 * * *$ & $1.5 * * *$ & $1.3 * * *$ & 0.9 & 1.2 \\
\hline Contract funding $(\%)$ & $1.5^{*}$ & 1.0 & 1.3 & 1.3 & $1.7 *$ \\
\hline Charity funding $(\%)$ & 0.9 & $0.5^{*}$ & $0.4^{*}$ & 0.9 & $0.5^{*}$ \\
\hline EU funding $(\%)$ & $2.3^{*}$ & 1.4 & 1.3 & 0.9 & 0.8 \\
\hline Variety of funding (\%) & $1.1 * *$ & 1.0 & 1.0 & 1.0 & $1.1 * *$ \\
\hline Intangible rewards & $0.97 * * *$ & 0.97 & $0.92 *$ & 0.95 & 1.0 \\
\hline Communication intensity & 1.0 & 0.9 & $0.8^{*}$ & 1.0 & 1.0 \\
\hline Pre-evaluation of applications & $1.1 * *$ & 1.0 & 1.0 & 1.0 & $0.91 *$ \\
\hline Autonomy (\% yes)* & $1.1 * *$ & 1.0 & 1.0 & 1.0 & $0.9 *$ \\
\hline Focus on expertise & $0.95 * *$ & 1.0 & 1.0 & 1.0 & 1.0 \\
\hline Committed research leader & 1.0 & 1.0 & 1.0 & 1.0 & $0.93 *$ \\
\hline Research time & 1.0 & $1.1 *$ & $0.9 *$ & $0.8^{*}$ & $0.7 *$ \\
\hline Networking (days) & 0.9 & 1.0 & $0.9 * * *$ & $0.9 * * *$ & 1.0 \\
\hline Age (years) & 1.0 & 1.0 & 1.0 & 1.0 & $1.3 *$ \\
\hline Experience (years) & 1.0 & 0.9 & $0.7 * *$ & $0.8^{* *}$ & 0.9 \\
\hline Publication counts (3 years) & 1.2 & $0.4^{*}$ & $0.5^{*}$ & $1.2 *$ & $1.8 *$ \\
\hline Citation counts & 1.0 & $0.3^{*}$ & $0.2^{*}$ & $0.9^{*}$ & 1.0 \\
\hline Publications per staff member & 0.9 & $0.4^{*}$ & $0.4^{*}$ & $1.1^{*}$ & 1.2 \\
\hline Citations per publication & $0.8 * * *$ & $0.6^{*}$ & $0.4^{*}$ & $0.6^{*}$ & $0.45^{*}$ \\
\hline
\end{tabular}

$* p<0.01 ; * * p<0.05 ; * * p<0.10$

\# The significance levels refer to the differences between the means

higher share of senior researchers has a positive effect. However, this is due to moderation effect of discipline (public health groups are different).

Higher variation in funding sources goes together with higher visibility. Yet, the direction of causality may work both ways. (1) Citations are a proxy for visibility, and high visibility may help group leaders to acquire more easily funds from different sources. (2) Inversely, group leaders who have a larger variety of funding may be bigger and therefore may have a more diverse portfolio and therefore are visible in different (scholarly) communities, resulting in more citations. Indeed, correlation between variety of funders and staff size is relatively large $(r=0.42)$. At the same time, groups depending on a single funding source may be less able to move into emerging hot issues, whereas groups with more funding sources do have this flexibility. In other words, reputation leads to more and 
diverse funding which again leads to more reputation - the Matthew effect (Merton 1988). Probably even more important than the variety of funders is the change in funding over time: average institutional funding went down from 42 to $32 \%$, and project funding (council, EC, contracts) went up from 52 to $64 \%$. Obviously, research leaders become less dependent on the organization and more dependent on external resources.

\section{Process aspects}

Communication intensity has a moderate positive effect on citation counts and citations per publications. The latter is also positively influenced by quality control (pre-evaluating funding applications). At the bivariate level, quite some other correlations were found between process variables and performance, but they disappeared from the full models.

The more committed a research leader is with research and the research group, the higher the scores on publications, citations and productivity. What a leader thinks and believes (research attitude and research leader attitude) seems at least as important as what he/she does as manager. A self-categorization as a dedicated scientist, committed to and active in the groups' research goes with higher performance.

Finally, networking activities contribute modest to publication counts, citation counts and productivity. A possible explanation is that networking in committees, editorial boards, conferences, and so on, increases the likelihood that submitted papers will be accepted, e.g., through a better understanding of procedures and priorities (Van den Besselaar 2012), that publications will find their way more easily to the right communities of interested peers, and that papers will be cited because the author is well known.

\section{Personal characteristics}

Age and experience do correlate with performance (Table 3). We did not find any effect any more in the basic and full models. We did not test for gender, as in this sample the share of female leaders is rather small.

\section{Limitations of the study}

Before formulating the conclusions, some limitations of the study should be discussed. Firstly, we measure management and leadership using a survey among group leaders, and have not surveyed team members. For several variables this would of course be informative, such as use of rewards, quality of communication, and the level of commitment with the groups' research. However, surveying all group members was far beyond the available resources for this project. Secondly, we have not included societal impact of research as performance dimension. For our sample, no correlation exists between scholarly and societal performance (Van der Weijden et al. 2012) -leaving open that other leadership characteristics may be needed for groups focusing on contributing to medical innovation and improving patient care. Thirdly, two independent variables (autonomy, quality control) are based on a single item-as the survey did not lead to reliable scales. The related findings should interpreted with care - as the validity and reliability of singleitem variables may be low. Finally, we used 'time spend for networking' as variable, but could have also included the size of the (inter)national co-author network. 


\section{Conclusions and discussion}

Although the literature endorses the positive contributions of academic leadership and group management to research performance, the specific effects of various leadership practices on performance were not disentangled yet. Reviewing the relevant literature, and using existing theories about group effectiveness and about environmental conditions, we developed a model to explain how various of academic leadership practices influence performance, whereas controlling for conditional factors. Table 6 gives an overview of the findings.

What factors $d o$ have impact on performance? Concerning resource strategy, group size and group composition matter. Larger groups have more publication output, and more visibility, but one should avoid too large groups as the productivity goes down with size: diminishing marginal returns to labor. A size of about 10-12 staff per research leader seems the optimum, and among our respondents 85 percent is below that size. Also the composition of the group is important for publication level, visibility and productivity, and especially groups with relatively many $\mathrm{PhD}$ students perform better. This suggests that flatter group structure is beneficial for performance, an important issue for further research. The main exception are public health groups where there is a positive relation between the share of senior staff and citation counts. The second part of resource strategy is funding. Diversity in funding sources is beneficial for visibility (total citations). Through diversity of funding, the research portfolio of a group may become more varied, implying larger audiences and the probability of more citations.

Networking matters, as time spend on network activities correlates positively with publication output and visibility, although the effect is not very strong. The more leaders perceive themselves as high committed and active researchers rather than as managers, and the stronger they are involved in the groups' research, the better is performance. Frequent communication within the group stimulates performance, although we only found a significant effect on citation counts.

Context variables make a difference. Public health research groups have lower scores on all performance variables than basic research, and in some cases this holds also for clinical research groups. This finding reflects disciplinary differences in publication and citation behavior. Whether the different disciplines require other leadership strategies and other research goals (Reale and Seeber 2011) could not be tested here-because of sample size. However, we aim at doing so using a next survey. The nature of the larger organization a group is embedded in is relevant too. We distinguished UMCs from PROs and the former show higher publication counts and productivity, but lower citations per publication.

What variables do not show impact on performance? Firstly, personal characteristics of the group leader do not seem to make a difference (age, management experience). These may, however, influence performance indirectly via the resource and process variables rather than directly. We did not test for that, to avoid making the analysis even more complex. Secondly, rewards, group members' autonomy, and time allocation do not seem to matter, nor did focus on maintaining scholarly expertise.

Where does this bring us? First of all, three variables have the clearest impact on performance: (1) Self-categorization of the group leader as a committed researcher who is heavily involved in the groups' research. The mechanism may be that such an identity functions as an example for the group members, which results in higher aspiration levels (Goodall 2009; Heinze et al. 2009); (2) Not too large and relatively flat groups consisting of (mostly two) research leaders and many young researchers; (3) Networking. This goes together with (4) a change in the funding landscape where group leaders become much 
Table 6 Overview of the results

\begin{tabular}{|c|c|c|c|c|}
\hline & $\begin{array}{l}\text { Publication } \\
\text { counts }\end{array}$ & $\begin{array}{l}\text { Citation } \\
\text { counts }\end{array}$ & $\begin{array}{l}\text { Publications per } \\
\text { staff member }\end{array}$ & $\begin{array}{l}\text { Citations per } \\
\text { publication }\end{array}$ \\
\hline \multicolumn{5}{|l|}{ Resource strategy } \\
\hline Staff size & + & + & - & \\
\hline$\% \mathrm{PhD}$ students & ++ & ++ & ++ & \\
\hline$\%$ Senior staff & & + & & \\
\hline$\%$ Full professors & & & + & \\
\hline Variety funders & & + & & \\
\hline \multicolumn{5}{|l|}{ Management } \\
\hline \multicolumn{5}{|l|}{ Use of rewards } \\
\hline Communication intensity & & + & & \\
\hline \multicolumn{5}{|l|}{ Autonomy } \\
\hline \multicolumn{5}{|l|}{ Quality control } \\
\hline \multicolumn{5}{|l|}{ Leadership } \\
\hline \multicolumn{5}{|l|}{ Maintaining expertise } \\
\hline \multicolumn{5}{|l|}{$\%$ Research time } \\
\hline Committed research leader & ++ & ++ & ++ & \\
\hline \multicolumn{5}{|l|}{ Networking } \\
\hline Days devoted to networking & + & + & & \\
\hline \multicolumn{5}{|l|}{ Personal characteristics } \\
\hline \multicolumn{5}{|l|}{ Age } \\
\hline \multicolumn{5}{|l|}{ Experience as group leader } \\
\hline \multicolumn{5}{|l|}{ Environmental conditions } \\
\hline Discipline (public health vs. basic research) & - & - & - & - \\
\hline Discipline (clinical vs. basic research) & & & & +++ \\
\hline Type organization (UMC vs. PRO) & ++ & & ++ & - \\
\hline System change (2007 vs. 2002) & & & & \\
\hline
\end{tabular}

more dependent on externally acquired project funding and on entrepreneurial skills required to do this.

Secondly, the same variables were found relevant for three of the four performance dimensions. Only citations per publication shows a different pattern, and is not significantly related to resource and process variables. Introducing organization type as context variable in the full model made the effect of the resource and process variables on this dimension of performance disappear. However, organizational characteristics still play a role-but now at a higher level of aggregation: related to differences between UMCs and PROs.

Up to now, the focus was on the level of the research group and its leader. However, our findings lead also to implications about the organization of research on a higher level. First of all, our results suggest that average quality is considerable higher in PROs than in UMCs. It would be important to further investigate this. Secondly, diversity in funding 
sources goes together with a declining role of institutional funding, and that may decrease the role of the research institute/university. More than the organizations' top-management, the group leader is dominant in responding to environmental demands (Gornitzka 1999; Pfeffer and Salancik 1978; Reale and Seeber 2011). In order to have success in acquiring funds from a diverse set of sources, research leaders become entrepreneurs, and need a high level of autonomy within their organizational environment (Etzkowitz 1998; Gulbrandsen and Smeby 2005). When groups become less dependent on institutional funding, research institutes lose their ability to influence research groups top-down (Sanz-Menéndez and Cruz-Castro 2003). The most the institute can probably do is to select excellent group leaders (Strandholm et al. 2004). Currently we observe increasing efforts of university boards to implement (new public) management strategies, focusing on top down agenda setting, and on top down development of university profiles and specialization. Our findings suggest that this may be counterproductive, as bottom up autonomy may be better for scientific excellence.

Finally, in this paper we focused on scholarly performance. However, research leaders may also have other objectives, e.g., translating research results into applications for patient care, or into new products and services that can be exploited commercially. The obvious question is whether societal impact requires specific managerial, leadership and organizational arrangements, something we will address in a follow up study.

Acknowledgments The authors acknowledge the very useful comments of two anonymous reviewers.

\section{References}

Adams, J. D., Black, G. C., Clemmons, J. R., \& Stephan, P. E. (2005). Scientific teams and institutional collaborations: Evidence from US universities, 1981-1999. Research Policy, 34(3), 259-285.

Allen, T. J., \& Sloan, A. P. (1970). Communication networks in R and D laboratories. $R$ \& D Management, 1(1), 14-21.

Allison, P. D. (1980). Inequality and scientific productivity. Social Studies of Science, 10, 163-179.

Allison, P. D., \& Long, J. S. (1990). Departmental effects on scientific productivity. American Sociological Review, 55(4), 469-478.

Amabile, T. M., Schatzel, E. A., Moneta, G. B., \& Kramer, S. J. (2004). Leader behaviors and the work environment for creativity: Perceived leader support. Leadership Quarterly, 15(1), 5-32.

Andrews, F. M. (1979). Motivation, diversity, and the performance of research units. In F. M. Andrews (Ed.), Scientific productivity The effectiveness of research groups in six countries. Cambridge: Cambridge University Press.

Andrews, F. M., \& Farris, G. F. (1967). Supervisory practices and innovation in scientific teams. Personnel Psychology, 20(4), 497-515.

Auranen, O., \& Nieminen, M. (2010). University research funding and publication performance-An international comparison. Research Policy, 39, 822-834.

Babu, A. R., \& Sing, Y. P. (1998). Determinants of research productivity. Scientometrics, 43(3), 309-329.

Baird, L. L. (1986). What characterizes a productive research department? Research in Higher Education, 25(3), 211-225.

Blackburn, R. T., Behymer, C. E., \& Hall, D. E. (1978). Research note - Correlates of faculty publications. Sociology of Education, 51(2), 132-141.

Bland, C. J., \& Ruffin, M. T. (1992). Characteristics of a productive research environment: Literature review. Academic Medicine, 67(6), 385-397.

Bonaccorsi, A., \& Daraio, C. (2005). Exploring size and agglomeration effects on public research productivity. Scientometrics, 63(1), 87-120.

Bornmann, L., Leydesdorff, L., \& Van den Besselaar, P. (2010). A meta-evaluation of scientific research proposals: Different ways of comparing rejected to awarded applications. Journal of Informetrics, 4(3), 211-220. 
Bornmann, L., Mutz, R., Neuhaus, C., \& Daniel, H. (2008). Citation counts for research evaluation: standards of good practice for analyzing bibliometric data and presenting and interpreting results. Ethics in science and environmental politics, 8, 93-102.

Bozeman, B., \& Corley, E. (2004). Scientists' collaboration strategies: implications for scientific and technical human capital. Research Policy, 33(4), 599-616.

Bozeman B, \& Boardman C. (2014). Research collaboration and team science: a state of the art review and agenda. Springer.

Braam, R., \& Van den Besselaar, P. (2010). Life cycles of research groups: the case of CWTS. Research Evaluation, 19, 173-184.

Braam R. \& Van den Besselaar P, (2014). Indicators for the dynamics of research organizations: a biomedical case study. Scientometrics, 99(3), 949-971.

Cameron, A. C., \& Trivedi, P. K. (1998). Regression analysis of count data. Cambridge: Cambridge University Press.

Carayol, N. (2003). Objectives, agreements and matching in science-industry collaborations: Reassembling the pieces of the puzzle. Research Policy, 32(6), 887-908.

Carayol, N., \& Matt, M. (2004). Does research organization influence academic production? Laboratory level evidence from a large European university. Research Policy, 33(8), 1081-1102.

Carayol, N., \& Matt, M. (2006). Individual and collective determinants of academic scientists' productivity. Information Economics and Policy, 18(1), 55-72.

Cardinal, L. B. (2001). Technological innovation in the pharmaceutical industry: the use of organizational control in managing research and development. Organization Science, 12(1), 19-36.

Cherchye, L., \& Abeele, P. V. (2005). On research efficiency-A micro-analysis of dutch university research in economics and business management. Research Policy, 34(4), 495-516.

Crane, D. (1965). Scientists at major and minor universities: A study of productivity and recognition. American Sociological Review, 30(5), 699-714.

Crane, D. (1972). Invisible colleges: Diffusion of knowledge in scientific communities. Chicago: University of Chicago Press.

Cummings, J. N., \& Cross, R. (2003). Structural properties of work groups and their consequences for performance. Social Networks, 25(3), 197-210.

De Jong, S. P. L., Van Arensbergen, P., Daemen, F., Van der Meulen, B., \& Van den Besselaar, P. (2011). Evaluation of research in context: an approach and two cases. Research Evaluation, 20(2), 61-72.

D'Este, P., \& Perkmann, M. (2011). Why do academics engage with industry? The entrepreneurial university and individual motivations. The Journal of Technology Transfer, 36, 316-339.

Dietz, J. S., \& Bozeman, B. (2005). Academic careers, patents, and productivity: Industry experience as scientific and technical human capital. Research Policy, 34(3), 349-367.

Dill, D. D. (1982). The management of academic culture-Notes on the management of meaning and social integration. Higher Education, 11(3), 303-320.

Dillman, D.A., Smyth J.D. \& Christian L.M. (2009) Internet, mail, and mixed-model surveys: the tailored design method. Hoboken: Wiley.

Dundar, H., \& Lewis, D. R. (1998). Determinants of research productivity in higher education. Research in Higher Education, 39(6), 607-631.

Etzkowitz, H. (1998). The norms of entrepreneurial science: cognitive effects of the new university-industry linkages. Research Policy, 27(8), 823-833.

Falk-Krzesinski, H. F., Contractor, N., Fiore, S. M., Hall, K. L., Kane, C., Keyton, J., et al. (2011). Mapping a research agenda for the science of team science. Research Evaluation, 20(2), 145-158.

Fox, M. F. (1992). Researh, teaching, and publication productivity: Mutuality versus competition in academia. Sociology of Education, 65(4), 293-305.

Fox, M. F., \& Mohapatra, S. (2007). Social-organizational characteristics of work and publication productivity among academic scientists in doctoral-granting departments. Journal of Higher Education, $78(5), 542-571$.

Frederiksen, L. F., Hemlin, S., \& Husted, K. (2004). The role of knowledge management in R\&D: a survey of Danish R\&D leaders' perceptions and beliefs. International Journal of Technology Management, 28(7-8), 820-839.

Gardner, W., Mulvey, E. P., \& Shaw, E. C. (1995). Regression analyses of counts and rates: poisson, overdispersed poisson, and negative binomial models. Psychological Bulletin, 118(3), 392-404.

Geuna, A. (2001). The changing rationale for European university research funding: Are there negative unintended consequences? Journal of Economic Issues, 35(3), 607-632.

Gladstein, D. L. (1984). Groups in context: A model of task group effectiveness. Administrative Science Quarterly, 29(4), 499-517. 
Gonzalez-Brambila, C., \& Veloso, F. M. (2007). The determinants of research output and impact: A study of Mexican researchers. Research Policy, 36, 1035-1051.

Goodall, A. H. (2009). Highly cited leaders and the performance of research universities. Research Policy, 38(7), 1079-1092.

Gornitzka, A. (1999). Governmental policies and organisational change in higher education. Higher Education, 38, 5-31.

Gottlieb, E. E., \& Keith, B. (1997). The academic research-teaching nexus in eight advanced-industrialized countries. Higher Education, 34(3), 397-419.

Groot, T., \& García-Valderrama, T. (2006). Research quality and efficiency. An analysis of assessments and management issues in Dutch economics and business research programs. Research Policy, 35, $1362-1376$.

Gulbrandsen, M., \& Smeby, J. C. (2005). Industry funding and university professors' research performance. Research Policy, 34(6), 932-950.

Gustad, J. W. (1960). The career decisions of college teachers. Washington, DC: Department of Health, Education and Welfare.

Hackett, E. J. (2005). Essential tensions: Identity, control, and risk in research. Social Studies of Science, 35(5), 787-826.

Haeussler, C., \& Colyvas, J. A. (2011). Breaking the ivory tower: Academic entrepreneurship in the life sciences in UK and Germany. Research Policy, 40, 41-54.

Haraszthy, A., \& Szántó, L. (1979). Some problems of research planning: data from Hungary compared to other Round 1 countries. In F. M. Andrews (Ed.), Scientific productivity. The effectiveness of research groups in six countries. Cambridge: Cambridge University Press.

Harris, G., \& Kaine, G. (1994). The determinants of research performance-A study of australian university economists. Higher Education, 27(2), 191-201.

Harvey, J., Pettigrew, A., \& Ferlie, E. (2002). The determinants of research group performance: towards mode 2? Journal of Management Studies, 39(6), 746-774.

He, Z. L., Geng, X. S., \& Campbell-Hunt, C. (2009). Research collaboration and research output: A longitudinal study of 65 biomedical scientists in a New Zealand university. Research Policy, 38(2), 306-317.

Heinze, T., Shapira, P., Rogers, J. D., \& Senker, J. M. (2009). Organizational and institutional influences on creativity in scientific research. Research Policy, 38, 610-623.

Hornbostel, S., Böhmer, S., Klingsporn, B., Neufeld, J., \& Von Ins, M. (2009). Funding of young scientist and scientific excellence. Scientometrics, 79(1), 171-190.

Jansen, D., Wald, A., Franke, K., Schmoch, U., \& Schubert, T. (2007). Third party research funding and performance in research. On the effects of institutional conditions on research performance of teams. Kolner Zeitschrift fur Soziologie und Sozialpsychologie, 59(1), pp. 125-149.

Johnes, G. (1988). Determinants of research output in economics departments in British-universities. Research Policy, 17(3), 171-178.

Jordan, J. M., Meador, M., \& Walters, S. J. K. (1988). Effects of department size and organization ont the research productivity of academic economists. Economics of Education Review, 7(2), 251-255.

Jordan, J. M., Meador, M., \& Walters, S. J. K. (1989). Academic research productivity, department size and organization: Further results. Economics of Education Review, 8(4), 345-352.

Katz, R. (1978a). Influence of job longevity on employee reactions to task characteristics. Human Relations, 31(8), 703-725.

Katz, R. (1978b). Job longevity as a situational factor in job satisfaction. Administrative Science Quarterly, 23(2), 204-223.

Katz, J. S. \& Martin, B. R. (1997). What is research collaboration? Research Policy, 26(1), 1-18.

Katz, R., \& Tushman, M. L. (1979). Communication patterns, project performance, and task characteristics-Empirical-evaluation and integration in an R and D setting. Organizational Behavior and Human Performance, 23(2), 139-162.

Keith, B., \& Babchuk, N. (1998). The quest for institutional recognition: a longitudinal analysis of scholarly productivity and academic prestige among sociology departments. Social Forces, 76(4), 1495-1533.

King, J. (1987). A review of bibliometric and other science indicators and their role in research evaluation. Journal of Information Science, 13, 261-276.

Knorr, K. D., \& Mittermeir, R. (1980). Publication productivity and professional position: Cross-national evidence on the role of organizations. Scientometrics, 2(2), 95-120.

Kretschmer, H. (1985). Cooperation structure, group-size and productivity in research groups. Scientometrics, 7(1-2), 39-53.

Kyvik, S. (1995). Are big university departments better than small ones. Higher Education, 30(3), $295-304$. 
Lam, A. (2011). What motivates academic scientists to engage in research commercialization: 'Gold', 'ribbon' or 'puzzle'? Research Policy, 40(10), 1354-1368.

Laredo, P., \& Mustar, P. (2000). Laboratory activity profiles: An exploratory approach. Scientometrics, 47(3), 515-539.

Leisyte, L., Enders, J., \& De Boer, H. (2008). The freedom to set research agendas-illusion and reality of the research units in the Dutch universities. Higher Education Policy, 21, 377-391.

Lepori, B., Van den Besselaar, P., Dinges, M., Potì, B., Reale, E., Slipersaeter, S., et al (2007). Indicators for comparative analysis of public project funding: concepts, implementation and evaluation. Research Evaluation, 16(4), 243-256.

Levin, S. G., \& Stephan, P. E. (1991). Research productivity over the life-cycle: Evidence for academic scientists. American Economic Review, 81(1), 114-132.

Long, J. S. (1978). Productivity and academic position in scientific career. American Sociological Review, 43(6), 889-908.

Long, J. S., Allison, P. D., \& McGinnis, R. (1979). Entrance into the academic career. American Sociological Review, 44(5), 816-830.

Long, J. S., \& McGinnis, R. (1981). Organizational context and scientific productivity. American Sociological Review, 46(4), 422-442.

Louis, K. S., Holdsworth, J. M., Anderson, M. S., \& Campbell, E. G. (2007). Becoming a scientist: The effects of work-group size and organizational climate. Journal of Higher Education, 78(3), 311-336.

Manjarrés-Henríquez, L., Gutiérrez-Gracia, A., \& Vega-Jurado, J. (2008). Coexistence of universityindustry relations and academic research: Barrier to or incentive for scientific productivity. Scientometrics, 76(3), 561-576.

Martin, B. R. (1996). The use of multiple indicators in the assessment of basic research. Scientometrics, 36(3), 343-362.

Martin, B. R., \& Irvine, J. (1983). Assessing basic research. Some partial indicators of scientific progress in radio astronomy. Research Policy, 12, 61-90.

Martin-Sempere, M. J., Garzon-Garcia, B., \& Rey-Rocha, J. (2008). Team consolidation, social integration and scientists' research performance: An empirical study in the Biology and Biomedicine field. Scientometrics, 76(3), 457-482.

McKeachie, W. (1979). Perspectives from psychology. In D. Lewis \& W. Becker (Eds.), Academic rewards in higher education. Massachusetts: Ballinger.

Mehra, A., Dixon, A. L., Brass, D. J., \& Robertson, B. (2006). The social network ties of group leaders: Implications for group performance and leader reputation. Organization Science, 17(1), 64-79.

Melin, G. (2000). Pragmatism and self-organization. Research collaboration on the individual level. Research Policy, 29, 31-40.

Merton, R. K. (1988). The Matthew effect in science, II Cumulative advantage and the symbolism of intellectual property. ISIS, 79, 606-623.

Mets, B., \& Galford, J. A. (2009). Leadership and management of academic anesthesiology departments in the United States. Journal of Clinical Anesthesia, 21(2), 83-93.

Moed, H. F. (2000). Bibliometric indicators reflect publication and management strategies. Scientometrics, 47(2), 323-346.

Mumford, M. D., Scott, G. M., Gaddis, B., \& Strange, J. M. (2002). Leading creative people: Orchestrating expertise and relationships. Leadership Quarterly, 13(6), 705-750.

Neuhaus, C., \& Daniel, H. D. (2009). A new reference standard for citation analysis in chemistry and related fields based on the sections of Chemical Abstracts. Scientometrics, 78(2), 219-229.

Oh, H. S., Chung, M. H., \& Labianca, G. (2004). Group social capital and group effectiveness: The role of informal socializing ties. Academy of Management Journal, 47(6), 860-875.

Oh, H. S., Labianca, G., \& Chung, M. H. (2006). A multilevel model of group social capital. Academy of Management Review, 31(3), 569-582.

Omta, S. W. F. (1995). Critical success factors in biomedical research and pharmaceutical innovation. Groningen: Rijks Universiteit Groningen.

Omta, S. W. F., \& De Leeuw, A. C. J. (1997). Management control, ucertainty, and performance in biomedical research in universities, institutes and companies. Journal of Engineering and Technology Management, 14, 223-257.

Oshagbemi, T. (2004). Age influences on the leadership styles and behaviour of managers. Employee Relations, 26(1), 14-29.

Pelz, D. C. (1956). Some social factors related to performance in a research organization. Administrative Science Quarterly, 1(3), 310-325.

Pelz, D. C., \& Andrews, F. M. (1966). Scientists in organizations. Productive Climates for Research and Development. New York-London-Sydney: Wiley. 
Perkoff, G. T. (1985). The research environment in family-practice. Journal of Family Practice, 21(5), 389-393.

Pfeffer, J., \& Salancik, G. R. (1978). The external control of organizations: A resource dependence perspective. New York: Harper \& Row.

Pineau, C., \& Levy-Leboyer, C. (1983). Managerial and organizational determinants of efficiency in biomedical research teams. In S. R. Epton, R. L. Payne, \& A. W. Pearson (Eds.), Managing interdisciplinary research (pp. 141-163). New York: Wiley.

Porter, S. R., \& Umbach, P. D. (2001). Analyzing faculty workload data using multilevel modeling. Research in Higher Education, 42(2), 171-196.

Prins, A. A. M. (1990). Behind the scenes of performance: Performance, practice and management in medical research. Research Policy, 19, 517-534.

Prpic, K. (1996). Characteristics and determinants of eminent scientists' productivity. Scientometrics, 36(2), 185-206.

Ramsden, P. (1994). Describing and explaining research productivity. Higher Education, 28(2), $207-226$.

Reagans, R., \& Zuckerman, E. W. (2001). Networks, diversity, and productivity: The social capital of corporate R\&D teams. Organization Science, 12(4), 502-517.

Reagans, R., Zuckerman, E., \& McEvily, B. (2004). How to make the team: Social networks vs. demography as criteria for designing effective teams. Administrative Science Quarterly, 49(1), 101-133.

Reale, E., \& Seeber, M. (2011). Organisation response to institutional pressures in Higher Education: the important role of the disciplines. Higher Education, 61, 1-22.

Reskin, B. F. (1979). Academic Sponsorship and Scientists Careers. Sociology of Education, 52(3), 129-146.

Sanz-Menéndez, L., \& Cruz-Castro, L. (2003). Coping with environmental pressures: public research organisations responses to funding crises. Research Policy, 32, 1293-1308.

Schubert, A., \& Braun, T. (1996). Cross-field normalization of scientometric indicators. Scientometrics, 36(3), 311-324.

Shin, J. C., \& Cummings, W. K. (2010). Multilevel analysis of academic publishing across disciplines: research preference, collaboration, and time on research. Scientometrics, 85, 581-594.

Sindermann, C. J. (1985). The joy of science. New York: Plenum.

Smeby, J. C., \& Try, S. (2005). Departmental contexts and faculty research activity in Norway. Research in Higher Education, 46(6), 593-619.

Spangenberg, J. F. A., Starmans, R., Bally, Y. W., Breemhaar, B., Nijhuis, F. J. N., \& Vandorp, C. A. F. (1990). Prediction of Scientific Performance in Clinical Medicine. Research Policy, 19(3), 239-255.

Stankiewicz, R. (1976). Research groups and the academic research organization. Sociologisk Forskning, 13(2), 20-32.

Stankiewicz, R. (1979). The size and age of Swedish academic research groups and their scientific performance. In F. M. Andrews (Ed.), Scientific productivity. The effectiveness of research groups in six countries (pp. 191-222). Cambridge: Cambridge University Press.

Strandholm, K., Kumar, K., \& Subramanian, R. (2004). Examining the interrelationships among perceived environmental change, strategic response, managerial characteristics, and organizational performance. Journal of Business Research, 57, 58-68.

Stvilia, B., Hinnant, C., Schindler, K., Worrall, A., Burnett, G., Burnett, K., et al. (2011). Team diversity and publication patterns in a scientific laboratory. Journal of American Society for Information Science and Technology, 62(2), 270-283.

Tijssen, R. J. W. (2003). Scoreboards of research excellence. Research Evaluation, 12(2), 91-103.

Tushman, M. L., \& Katz, R. (1980). External Communication and Project Performance-An Investigation into the Role of Gatekeepers. Management Science, 26(11), 1071-1085.

Urwick, L. F. (1956). The manager's span of control. Harvard Business Review, 34, 39-47.

Van den Besselaar, P. (2012). Grant committee membership: service or self-service? Journal of Informetrics, 6, 580-585.

Van den Besselaar, P., \& Leydesdorff, L. (2009). Past performance, peer review, and project selection: A case study in the social and behavioral sciences. Research Evaluation, 18(4), 273-288.

Van der Weijden, I., De Gilder, D., Groenewegen, P., \& Geerling, M. (2008a). Organizational culture, performance and career choices of Ph.D.s: A case study of Dutch Medical Researchers. Higher Education Policy, 21, 305-321.

Van der Weijden, I., De Gilder, D., Groenewegen, P., \& Klasen, E. (2008b). Implications of managerial control on performance of Dutch academic (bio)medical and health research groups. Research Policy, 37, 1616-1629. 
Van der Weijden, I., Verbree, M., \& Van den Besselaar, P. (2012). From bench to bedside: an exploratory study of the societal orientation in Dutch biomedical and health research groups. Science and Public Policy, 39(3), 285-303.

Van Raan, A. F. J. (2004). Measuring science. Capita selecta of current main issues. In H. F. Moed, W. Glanzel, \& U. Schmoch (Eds.), Handbook of quantitative science and technology research (pp. 19-50). Dordrecht: Kluwer Academic Publishers.

Van Rijnsoever, F. J., Hessels, L. K., \& Vandeberg, R. L. J. (2008). A resource-based view on the interactions of university researchers. Research Policy, 37, 1255-1266.

Verbree, M., Van der Weijden, I., \& Van den Besselaar, P. (2013a). Academic leadership of high-performing research groups. In S. Hemlin, C. M. Allwood, B. Martin, \& M. Mumford (Eds.), Creativity and leadership in science, technology, and innovation. London: Routledge.

Verbree, M., Van der Weijden, I., \& Van den Besselaar, P. (2013b). Age, generation and life cycle effects on academic leadership. In S. Hemlin, C. M. Allwood, B. Martin, \& M. Mumford (Eds.), Creativity and leadership in science, technology, and innovation. London: Routledge.

Visart, N. (1979). Communication between and within research units. In F. M. Andrews (Ed.), Scientific productivity The effectiveness of research groups in six countries (pp. 223-252). Cambridge: Cambridge University Press/UNESCO.

Von Tunzelmann, N., Ranga, M., Martin, B., \& Geuna, A. (2003). The effects of size on research performance: A SPRU review: SPRU Science and Technology Policy Research. Document Number).

Wagner, C. S. (2005). Six case studies of international collaboration in science. Scientometrics, 62(1), 3-26.

Whitley, R. (2000). The intellectual and social organization of the sciences (2nd ed.). New York: Oxford University Press.

Wouters, P. (1999). The citation culture. PhD thesis University of Amsterdam.

Zaleznik, A. (1977). Managers and leaders. Are they different? Harvard Business Review, 55(3), 67-78. 